\title{
ERRATUM
}

Carlo Baldari $\cdot$ Miguel Videira $\cdot$ Francisco Madeira

Joaquim Sergio · Laura Guidetti

\section{Lactate removal during active recovery related to the individual anaerobic and ventilatory thresholds in soccer players}

\section{Eur J Appl Physiol (2004) 93:224-230}

The correct versions are respectively:

In the pdf version and in the printed article, the following abbreviations were incorrect:

$\dot{\mathrm{V}} \mathrm{O}_{2 \max }$ (as in the Abstract, line 7)

$\dot{V} \mathrm{O}_{2}$ (as on page 225, left column, Methods, Subjects, line 7)

$V \dot{V} \mathrm{O}_{2 \max }$

$V \dot{V} \mathrm{O}_{2}$

$\dot{V}_{\mathrm{E}}$ (as printed on page 226, right column, Pre-session $V \dot{V}_{\mathrm{E}}$

The online version of the original article can be found at http:// dx.doi.org/10.1007/s00421-004-1203-5

C. Baldari $(\bowtie) \cdot$ L. Guidetti

Istituto Universitario di Scienze Motorie (IUSM),

Piazza Lauro De Bosis, 15, 00194 Rome, Italy

E-mail: baldari@iusm.it

Tel.: + 39-06-36733543

Fax: + 39-06-3613065

M. Videira

Universidade de Tras-os-Montes e Alto Douro (UTAD),

Vila Real, Portugal

F. Madeira · J. Sergio

Facultade de Motricidade Humana, UT Universidade

Técnica de Lisboa, Lisbon, Portugal 